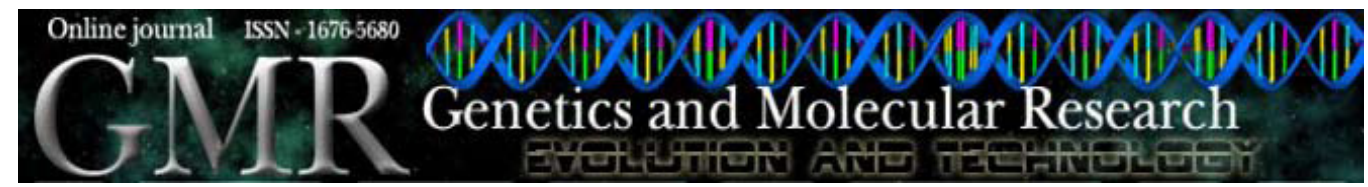

Technical Note

\title{
Polymorphic microsatellite loci from two enriched genomic libraries for the genetic analysis of the miiuy croaker, Miichthys miiuy (Sciaenidae)
}

\author{
R.X. Wang ${ }^{1,2 *}$, T.J. Xu ${ }^{2 *}$, Y.N. Sun ${ }^{2}$ and G.Y. He ${ }^{1}$ \\ ${ }^{1}$ China-UK HUST-RRes Genetic Engineering and Genomics Joint Laboratory, \\ College of Life Science and Technology, \\ Huazhong University of Science and Technology, Wuhan, P.R. China \\ ${ }^{2}$ Key Laboratory for Marine Living Resources and Molecular Engineering, \\ College of Marine Science, Zhejiang Ocean University, Zhoushan, P.R. China \\ *These authors contributed equally to this study. \\ Corresponding author: G.Y. He \\ E-mail: hegy@hust.edu.cn
}

Genet. Mol. Res. 9 (2): 931-934 (2010)

Received January 28, 2010

Accepted February 23, 2010

Published May 18, 2010

DOI 10.4238/vol9-2gmr806

\begin{abstract}
Twelve polymorphic microsatellites from the (AG) $)_{13}$ and (CA $)_{13}$ enriched genomic libraries of Miichthys miiuy were isolated and characterized in a test population; the number of alleles ranged from two to nine. The observed and expected heterozygosities ranged from 0.1923 to 1.0000 and from 0.2633 to 0.8337 , respectively. Three loci deviated from Hardy-Weinberg equilibrium, and linkage disequilibrium between five pairs of loci was significant. These polymorphic microsatellite loci can be used for genetic diversity analysis and molecular-assisted breeding of M. miiuy.
\end{abstract}

Key words: Miichthys miiuy; Microsatellite; Molecular marker 


\section{INTRODUCTION}

Miiuy croaker, Miichthys miiuy, is a promising marine fish species for culture in China and is distributed throughout eastern China (Zhang and Hong, 2000; Shan et al., 2008a,b). High mortality and poor growth have been frequently found during artificial larval rearing, which is hindering the mass production of this fish (Shan et al., 2009). Hence, an important approach to improve this situation is to culture strains of fish with enhanced resistance to some major diseases. Artificial breeding of miiuy croaker with disease resistance and better growth has been conducted in China. However, molecular marker-assisted selective breeding is still lacking because it demands analysis of genetic characteristics and quantitative trait locus (QTL) markers of selected strains using molecular markers. Although it is an important commercial fish species, little is known about the genetic information of miiuy croaker. There are no abundant molecular markers such as microsatellites isolated from this species. Lack of enough polymorphic molecular markers has limited development of molecular phylogeny, population structure, conservation genetics, and assisted selective breeding in this species. Thus, screening for polymorphic microsatellite or other molecular markers is necessary for analyzing genetic information in the miiuy croaker. Microsatellites are useful molecular markers to study population structure and genetic evolutionary information (Liu et al., 2009). In the present study, 12 polymorphic microsatellite DNA markers were developed from two dinucleotide-enriched genomic libraries created using fast isolation by amplified fragment length polymorphism of sequences containing repeats (FIASCO method; Zane et al., 2002).

\section{MATERIAL AND METHODS}

Thirty individuals of miiuy croaker were captured from the Zhoushan fishing ground of the East Sea. Total genomic DNA was extracted from gills using the TIANamp Genomic DNA Kit (Tiangen) following manufacturer instructions. Two enriched partial genomic libraries for the repeat motif $(\mathrm{AG})_{13}$ and $(\mathrm{CA})_{13}$ were constructed essentially using DNA from one individual and following the FIASCO protocol. In brief, genomic DNA was digested using the MseI restriction enzyme (MBI) and DNA fragments between 300 and $1000 \mathrm{bp}$ were isolated on $1.2 \%$ agarose gel. These fragments were ligated to adapters OligoA (5'-TACTCAGGACTCAT-3') and OligoB (5'-GACGATGAGTCCTGAG-3'), and then amplified by polymerase chain reaction (PCR) using MseI-N primers (5'-GATGAGTCCTGAGTAAN-3'). Then genomic DNA fragments containing simple sequence repeat (SSR) sequences were captured by hybridization to $(\mathrm{AG})_{13}$ and $(\mathrm{CA})_{13}$ biotin-labeled probes. Captured fragments were ligated to pGEM-T vectors (Promega) and transformed into TOP10 competent cells following the standard protocol. Positive clones $(\mathrm{N}=106)$ were screened via PCR with T7/SP6 primers, sequenced using T7 primer on an ABI 3730 automated sequencer. From the two libraries, 91 clones were sequenced successfully and 55 sequences contained sufficient repeat motifs. Some possessed only three to seven repeats, which held less potential for useful polymorphism. Primers for these loci were designed using the PRIMER PREMIER 5.0 software. Forty-four primer pairs were designed from 44 sequences as the remaining SSR sequences were too close to the cloning site to design primers.

Polymorphism at each locus was determined using 30 individuals. PCR amplifications were carried out in $25-\mu \mathrm{L}$ volumes containing $2.5 \mu \mathrm{L} 10 \mathrm{X}$ PCR buffer, $1.5 \mathrm{mM} \mathrm{MgCl}_{2}, 0.2 \mathrm{mM}$ 
dNTPs, $0.2 \mu \mathrm{M}$ of the forward and reverse primers, and 1.5 units of Taq polymerase (Takara). Cycling conditions were $94^{\circ} \mathrm{C}$ for 4 min followed by 30 cycles of $94^{\circ} \mathrm{C}$ for $40 \mathrm{~s}$, annealing temperature for $45 \mathrm{~s}$ (see Table 1), and $72^{\circ} \mathrm{C}$ for $40 \mathrm{~s}$, followed by 1 cycle of $72^{\circ} \mathrm{C}$ for $5 \mathrm{~min}$ and then holding at $4^{\circ} \mathrm{C}$. PCR amplification was performed on an ABI 9700 thermalcycler. Denatured amplified products were separated on $6 \%$ denaturing polyacrylamide (19:1 acrylamide:bisacrylamide) gels using silver staining (Xu et al., 2009). A denatured pBR322 DNA/MspI molecular weight marker (Tiangen) was used as a size standard to identify alleles (Xu et al., 2009). POPGENE32 (Yeh and Boyle, 1997) and ARLEQUIN 3.11 softwares (Schneider et al., 2000) were used to calculate the number of alleles, observed and expected heterozygosity, violation of Hardy-Weinberg equilibrium (HWE) expectations, and genotypic linkage disequilibrium. All results for multiple tests were corrected using Bonferroni's correction (Rice, 1989).

\section{RESULTS AND DISCUSSION}

Details for the newly developed 12 microsatellite loci and variability measures across 30 individuals are summarized in Table 1.

\begin{tabular}{|c|c|c|c|c|c|c|c|}
\hline Locus & $\begin{array}{c}\text { GenBank } \\
\text { accession No. }\end{array}$ & Repeat motif & Primer (5'-3') & $\operatorname{Tm}\left({ }^{\circ} \mathrm{C}\right)$ & Size range (bp) & $\mathrm{N}$ & $H_{\mathrm{O}} H_{\mathrm{E}}$ \\
\hline Mimi-1 & GU084247 & $(\mathrm{GT})_{9}$ & $\begin{array}{l}\text { F: TAACCCCACAGAAAAGAA } \\
\text { R: ATGCAGAGGTCAATAGACTT }\end{array}$ & 48 & $207-213$ & 3 & $\begin{array}{l}0.4074 \\
0.3431\end{array}$ \\
\hline Mimi-3 & GU084248 & $(\mathrm{CA})_{9}$ & $\begin{array}{l}\text { F: CATTTTCCACGAGGTTAT } \\
\text { R: GAAGAAGACATTTGCTGA }\end{array}$ & 48 & $177-193$ & 6 & $\begin{array}{l}0.2963 * \\
0.7743\end{array}$ \\
\hline Mimi-4 & GU084249 & $(\mathrm{GT})_{11}$ & $\begin{array}{l}\text { F: CATCATAAATAAGCACAGGGAG } \\
\text { R: TCGGAGCAGGGCTAAAGT }\end{array}$ & 50 & $140-160$ & 8 & $\begin{array}{l}0.5217 \\
0.6773\end{array}$ \\
\hline Mimi-6 & GU084250 & $(\mathrm{CA})_{23}$ & $\begin{array}{l}\text { F: CTATGCCGAAACACGGAGAA } \\
\text { R: GCCGCAAGGATGGAATGAC }\end{array}$ & 51 & $147-163$ & 9 & $\begin{array}{l}1.0000^{*} \\
0.8112\end{array}$ \\
\hline Mimi-12 & GU084251 & $(\mathrm{CA})_{10}$ & $\begin{array}{l}\text { F: ATTGGCTATAAATCCTACTGG } \\
\text { R: ACAACTTCATCGCACTCC }\end{array}$ & 50 & $151-179$ & 8 & $\begin{array}{l}0.3571 * \\
0.8377\end{array}$ \\
\hline Mimi-15 & GU084252 & $(\mathrm{CA})_{15}$ & $\begin{array}{l}\text { F: CACTCTGGTTTTCATTCA } \\
\text { R: GTACGTCGAGCAAAGTAA }\end{array}$ & 49 & $124-142$ & 8 & $\begin{array}{l}0.5556 \\
0.8036\end{array}$ \\
\hline Mimi-18 & GU084253 & $(\mathrm{CT})_{9} \mathrm{~N}_{7}(\mathrm{CT})_{7}$ & $\begin{array}{l}\text { F:CAGGCAGGAAGCAGGAT } \\
\text { R: AAGATGCGCCCATTCTC }\end{array}$ & 52 & $141-147$ & 4 & $\begin{array}{l}0.5172 \\
0.5783\end{array}$ \\
\hline Mimi-19 & GU084254 & $(\mathrm{GA})_{9}$ & $\begin{array}{l}\text { F: GGAGGAAAAGGGTAGAA } \\
\text { R: CAAAAGGCCTGTCTCAT }\end{array}$ & 50 & $142-158$ & 5 & $\begin{array}{l}0.1923 \\
0.4223\end{array}$ \\
\hline Mimi-24 & GU084255 & $(\mathrm{AG})_{21} \mathrm{GCA}(\mathrm{G})_{12} \mathrm{~N}_{22}(\mathrm{C})_{12}$ & $\begin{array}{l}\text { F: TCGATACAGCTGACGAGA } \\
\text { R: GAGACTCAGGCCCAGAG }\end{array}$ & 51 & $138-142$ & 3 & $\begin{array}{l}0.2917 \\
0.2633\end{array}$ \\
\hline Mimi-28 & GU084256 & $(\mathrm{TC})_{11}$ & $\begin{array}{l}\text { F:AAAACAGCCTGTCGGTC } \\
\text { R: CGGTTGAAGCAAACATAAT }\end{array}$ & 48 & $100-114$ & 5 & $\begin{array}{l}0.2857 \\
0.3721\end{array}$ \\
\hline Mimi-30 & GU084257 & $(\mathrm{TC})_{10}$ & $\begin{array}{l}\text { F: TGGGAGCACTAAAGAGGC } \\
\text { R: GAGGACCAGAGGAAAGAAGAG }\end{array}$ & 51 & $143-147$ & 2 & $\begin{array}{l}0.2917 \\
0.4388\end{array}$ \\
\hline Mimi-39 & GU084258 & $(\mathrm{GA})_{12}$ & $\begin{array}{l}\text { F: ATCACGGCAGGAAAAGA } \\
\text { R: TGTATGAGAACATCTCGTTG }\end{array}$ & 49 & $93-113$ & 7 & $\begin{array}{l}0.6400 \\
0.8253\end{array}$ \\
\hline
\end{tabular}

$H_{\mathrm{O}}=$ observed heterozygosity; $H_{\mathrm{E}}=$ expected heterozygosity; $\mathrm{N}=$ number of alleles; $\mathrm{Tm}=$ annealing temperature. *Indicates significant deviation from HWE after Bonferroni correction $(\mathrm{P}<0.0042)$.

In total, 12 of 44 amplicons from the microsatellite-enriched genomic libraries were successfully amplified and shown to be polymorphic in the miiuy croaker. The 12 sequences containing microsatellite loci were deposited in GenBank (GU084247-GU084258). No similarity was found between the 12 microsatellites and the published sequences in GenBank. The 
number of alleles per locus ranged from 2 to 9 , and observed and expected heterozygosity ranged from 0.1923 to 1.0000 and from 0.2633 to 0.8337 , respectively. The remaining 32 loci were monomorphic and failed to amplify. Three loci (Mimi-3, Mimi-6 and Mimi-12) deviated from the HWE expectations in the sampled population after Bonferroni's correction (adjusted $\mathrm{P}$ value $=0.0042$ ); the remaining 9 loci conformed to HWE. Mimi-3 and Mimi-12 deviated from the HWE possibly due to the presence of null alleles or the existence of subpopulations, but it is interesting to note that the locus Mimi-6 has the highest number of repeats and the most alleles, and the observed heterozygosity of 1 is very extreme. Furthermore, null alleles were found in five loci (Mimi-3, Mimi-12, Mimi-15, Mimi-19, and Mimi-30) and stuttering errors were found in one locus (Mimi-3) using MICRO-CHECKER (Van Oosterhout et al., 2004) (Bonferroni's correction), but no evidence of allelic dropout was found in any of the loci (Bonferroni's correction). In total, 66 pairwise tests for linkage disequilibrium among the 12 loci were non-significant $(\mathrm{P}>0.05$, adjusted $\mathrm{P}$ value $=0.0008)$ except for five pairs of loci (Mimi-3 and Mimi-12; Mimi-3 and Mimi-19; Mimi-3 and Mimi-30; Mimi-4 and Mimi-30; Mimi-24 and Mimi-30). These polymorphic microsatellite loci in miiuy croaker will enable studies of the genetic variation, population structure, conservation genetics, and molecular assisted selective breeding of the miiuy croaker in the future.

\section{ACKNOWLEDGMENTS}

Research supported by the Research Foundation of Zhejiang Province (\#2007C02001, \#2008C22026 and \#20070430) and the National Technology R\&D Program of China (\#2007BAD43B08).

\section{REFERENCES}

Liu YG, Liu CY, Li FZ, Li ZX, et al. (2009). Development of microsatellite markers in sea perch, Lateolabrax japonicus, from codominant amplified fragment length polymorphism bands. J. World Aquacult. Soc. 40: 522-530.

Rice WE (1989). Analyzing tables of statistical tests. Evolution 43: 223-225.

Schneider S, Roessli D and Excoffier L (2000). ARLEQUIN: a software for population genetics data analysis, version 2.000. University of Geneva, Geneva.

Shan XJ, Cao L, Huang W and Dou SZ (2008a). Feeding, morphological changes and allometric growth during starvation in miiuy croaker larvae. Environ. Biol. Fishes 86: 121-130.

Shan XJ, Xiao ZZ, Huang W and Dou SZ (2008b). Effects of photoperiod on growth, mortality and digestive enzymes in miiuy croaker larvae and juveniles. Aquaculture 281: 70-76.

Shan XJ, Huang W, Cao L, Xiao ZZ, et al. (2009). Ontogenetic development of digestive enzymes and effect of starvation in miiuy croaker Miichthys miiuy larvae. Fish Physiol. Biochem. 35: 385-398.

Van Oosterhout C, Hutchinson WF, Wills DPM and Shipley P (2004). MICRO-CHECKER: software for identifying and correcting genotyping errors in microsatellite data. Mol. Ecol. Notes 4: 538.

Xu TJ, Liao XL, Shao CW, Ji XS, et al. (2009). Isolation and characterization of polymorphic microsatellite DNA markers in the rock bream (Oplegnathus fasciatus). Conserv. Genet. 10: 527-529.

Yeh FC and Boyle TJB (1997). Population genetic analysis of co-dominant and dominant markers and quantitative traits. Belg. J. Bot. 129-157.

Zane L, Bargelloni L and Patarnello T (2002). Strategies for microsatellite isolation: a review. Mol. Ecol. 11: 1-16.

Zhang QY and Hong WS (2000). Status and prospects of artificial propagation and breeding technique of marine fish in China in the 1990s (in Chinese). Mod. Fish. Info. 15:3-6. 